\title{
Evaluation of Alternative Substrates and Fertilizer Regimes for the Nursery Cultivation of Phyllostachys pubescens (Carrière) J. Houz.
}

\author{
Federica LARCHER*, Luca BATTISTI, Walter GAINO, \\ Marco DEVECCHI
}

University of Turin, Department of Agricultural, Forest and Food Sciences, Largo Paolo Braccini, 2 - 10095 Grugliasco (TO), Italy;
federica.larcher@unito.it ( ${ }^{*}$ correspondingauthor); luca.battisti@unito.it; walter.gaino@unito.it; marco.devecchi@unito.it

\begin{abstract}
The economic importance of the bamboo cultivation in Asia is well known, but the recent rise of interest in Europe required more deep studies on growing techniques. Among the bamboo species, the Phyllostachys pubescens (Carrière) J. Houz. is appreciated for its multiple uses: landscaping, timber and shoots production. In order to identify the best and sustainable combination of substrates and fertilization regimes, a nursery experimental trial was performed in 2016. Eight treatments (four substrates and two fertilization regimes) with 256 young plantlets divided into four randomized blocks were evaluated. The substrates used were: $40 \%$ peat, $40 \%$ coconut fibers, $20 \%$ pumice (standard substrate, $S 1$ ); $30 \%$ peat, $40 \%$ coconut fibers, $10 \%$ rice husk, $20 \%$ pumice (S2); $30 \%$ peat, $40 \%$ coconut fibers, $20 \%$ rice husk, $10 \%$ pumice (S3); $30 \%$ peat, $40 \%$ coconut fibers, $20 \%$ wood fibers, $10 \%$ pumice (S4). The two fertilization regimes were: $1.6 \mathrm{~g} \mathrm{l}^{-1}$ (A) and $0.8 \mathrm{~g} \mathrm{l}^{-1}$ (B) NPK (16-11-10) Osmocote Exact ${ }^{\circ}$. All substrates were supplemented with a fungal inoculum $\left(2.5 \mathrm{~g} \mathrm{l}^{-1}\right)$ and corrected with $2.5 \times 10^{-3} \mathrm{~g} \mathrm{l}^{-1}$ of $\mathrm{CaCO}_{3}$. The number of culms and leaves and the SPAD values of six plants of each blocks were monthly measured. Fresh and dry weights, before and after cultivation was recorded. Data were statistically analyzed. Results showed that rice husk should be used only in low percentage, but wood fiber can be more suitable for bamboo cultivation. The combination of alternative materials and low fertilization regimes (S1_B and S4_B) should be the key for a more sustainable cultivation for potted Phyllostachys pubescens in Europe.
\end{abstract}

Keywords: coconut fibers, moso bamboo, nutrition, peat substitute, rice husk, seedlings, wood fibers

\section{Introduction}

Man intentionally introduced alien plants into native ecosystems, which often resulted in substitution in those ecosystems (Komatsu et al., 2012).

Bamboo is the vernacular or common term for members of a particular taxonomic group of a large woody grass, widely distributed in all the tropics, subtropics and temperate zones of the world (Scurlock et al., 2000). There are about 1250 species in 90 genera of bamboo in the world (Lobovikov et al., 2012). Phyllostachys pubescens (synonym of $P$. edulis) is commercially one the most important species providing timber and the most predominant source of bamboo shoots (Lin et al., 2014).

Phyllostachys pubescens was introduced in Japan about 350 years ago mainly to produce heaths and young edible shoots. This kind of cultivation has been growing rapidly in Europe since few years. Its cane has good commercial value and is often used in the construction of buildings or furniture, mats, musical instruments and artisanal crafts (Yang et al., 2016).
By requiring only five years to grow from ripe bamboo shoots, mature bamboo culms can be harvested for use, indicating that bamboo is a superior species for carbon storage, especially when grown with good practices (Yen, 2015; Yen, 2016). Although bamboo heaps cannot be harvested up to five years, biomass is rapidly accumulating in early growth phases (Yen et al.; 2010; Yen and Lee 2011).

Moso bamboo (Phyllostachys pubescens) has many advantages over other plants such as rapid growth, biomass production reaching $82 \mathrm{t} \mathrm{hm}^{-2}$ of dry weight and a strong adaptation ability to different environments (Chen $e t$ al., 2015; Chen et al., 2016). In Europe, there is an increasing demand of bamboo seedlings by farmers who are interested in cultivating bamboo for commercial purposes. The request of these plants leads to elevated need for production of seedlings in the nurseries.

The aim of this study was to identify a combination of different substrates and fertilization regimes suitable for a sustainable, commercial production of bamboo plants in nurseries. This research was set up in collaboration with an Italian nursery which produces and markets moso bamboo. 


\section{Materials and Methods}

\section{Experimentaldesign}

The research was carried out at Vivai Purpurea s.r.l., a commercial nursery located in Piobesi Torinese (Piedmont Region, Italy). The annual average temperature is $12.8^{\circ} \mathrm{C}$. The annual average precipitation is $798 \mathrm{~mm}$. The hottest month is July, with an average temperature of $23.4^{\circ} \mathrm{C}$.

Four different substrates with two different fertilization regimes were tested. A completely randomized greenhouse experiment with four replications was carried out from June to September 2016 (Fig. 1).

Alternative materials were chosen as potting media in order to reduce the use of peat and to enhance the general media sustainability. Local recycled products, such as rice husk and wood fibers, coming from other agricultural productions available near the study area were therefore used. The composition of the four substrates were: $40 \%$ peat, $40 \%$ coconut fibers, $20 \%$ pumice (standard substrate, $S 1$ ); $30 \%$ peat, $40 \%$ coconut fibers, $10 \%$ rice husk, $20 \%$ pumice (S2); $30 \%$ peat, $40 \%$ coconut fibers, $20 \%$ rice husk, $10 \%$ pumice (S3); $30 \%$ peat, $40 \%$ coconut fibers, $20 \%$ wood fibers, $10 \%$ pumice (S4).

The two fertilization regimes were: $1.6 \mathrm{~kg} \mathrm{~m}^{-3}$ (A) and 0.8 $\mathrm{kg} \mathrm{m}^{-3}$ (B) NPK (16-11-10) Osmocote Exact. To all the substrates a fungal inoculum $\left(2.5 \mathrm{~kg} \mathrm{~m}^{-3}, \mathrm{Mico}^{\circ}\right.$ - Evergreen Bios) and also a corrective limestone-based calcium carbonate $\left(2.5 \times 10^{-3} \mathrm{~g} \mathrm{l}^{-1}\right)$ were added. The first treatment S1_A was considered as the reference one.

The substrates composition and their physical and chemical properties without fertilizer are presented in Table 1.

A total number of 40 pots $(0.882 \mathrm{l})$ for each treatment was prepared. In each pot one bamboo seedling (one month old) was transplanted. Totally, there were 1,280 potted plants divided into four randomized blocks.

\section{Data analysis}

At the beginning and at the end of the experiment, fresh and dry weight of the aerial and of the rooted part of the plants was measured, using a precision balance with two decimals of sensitivity. To assess the dry weight of the plants, they were placed in metal capsules and then placed in a $70{ }^{\circ} \mathrm{C}$ thermoregulated air heater until reaching a constant weight.

Ten plants of each treatment were placed in the air heater. At the beginning of the test, the average dry weight \pm standard deviation of the aerial part was $0.40 \mathrm{~g} \pm 0.09$ whereas that of the underground part was $0.18 \mathrm{~g} \pm 0.01$. Considering the fresh

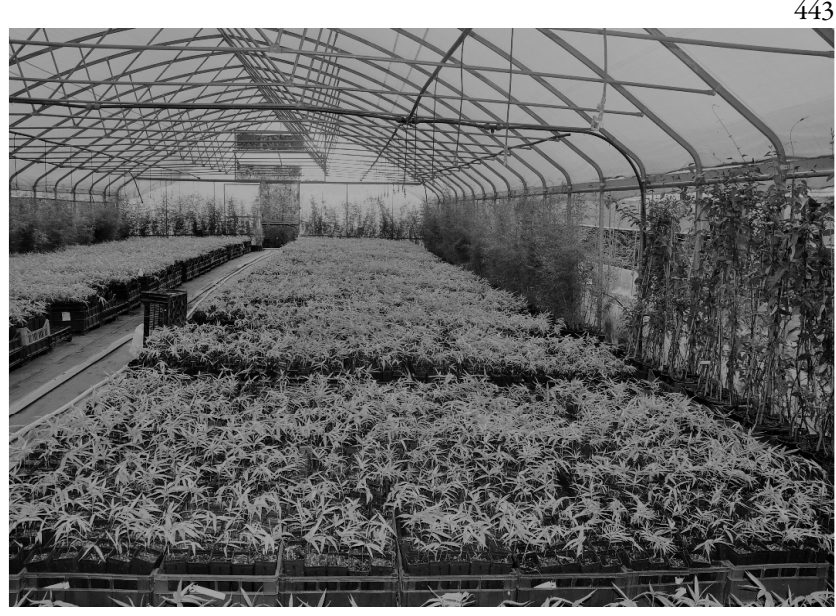

Fig. 1. The experimental design in greenhouse conditions

weight it was possible to observe how weight loss in the aerial part was about $52 \%$ while in the underground part was about $26 \%$.

The experimental design included the analysis of 256 plants, in which the total number of culms and leaves were monthly measured. Moreover the SPAD values (Chlorophyll meter SPAD-502, Minolta) were analysed choosing two leaves of each plant as the average measure of two values in different leaf positions.

\section{Statistical analysis}

Statistical differences were highlighted by a one-way ANOVA followed by the Duncan's Multiple Range Test ( $\mathrm{p}<$ 0.05), using SPSS statistical package (Version 22.0, SPSS Inc., Chicago, IL).

\section{Results and Discussion}

Generally, the period from bamboo shoot sprouting out to bamboo timber being cut down is about six years. However the most rapid growth period appears from one to six weeks after bamboo shoot sprouting out and the whole bamboo grows up and reaches the maximum height and width (Wu et al., 2009). Absorption of water and nutrients from the soil by bamboo depends on the growth habit and functionality of their roots and rhizomes. It is generally agreed that the root system of bamboo does not usually elongate to great soil depth, but rather develops a profuse root mat of highly efficient fine roots and

Table 1. Composition and chemical properties of substrates (mean value \pm standard deviation)

\begin{tabular}{|c|c|c|c|c|c|c|c|c|}
\hline Substrates & Composition & $\mathrm{pH}^{1}$ & $\begin{array}{c}\mathrm{EC}^{1} \\
\left(\mu \mathrm{S} \mathrm{cm}^{-1}\right)\end{array}$ & $\begin{array}{l}\text { Humidity } \\
\text { (\%) }\end{array}$ & $\begin{array}{c}\text { Total } \mathrm{N}^{2} \\
(\%)\end{array}$ & $\begin{array}{l}\text { Total C } \\
(\%)\end{array}$ & $\begin{array}{l}\text { Total } \mathrm{P}^{3} \\
\left(\mu \mathrm{P} \mathrm{g} \mathrm{g}^{-1}\right)\end{array}$ & $\begin{array}{l}\text { Total } \mathrm{K}^{3} \\
\left(\mu \mathrm{g} \mathrm{K} \mathrm{g}^{-1}\right)\end{array}$ \\
\hline S1 & $\begin{array}{c}40 \% \text { peat }+40 \% \text { coconut fibers } \\
+20 \% \text { pumice }\end{array}$ & 7.2 & 105 & 55.6 & $0.28 \pm 0.01$ & $24.8 \pm 0.32$ & $260^{*}$ & 6100 \\
\hline S2 & $\begin{array}{l}30 \% \text { peat }+40 \% \text { coconut fibers }+10 \% \text { rice husk } \\
+20 \% \text { pumice }\end{array}$ & 7.1 & 62 & 77.2 & $0.27 \pm 0.04$ & $25.9 \pm 1.34$ & 298 & 6200 \\
\hline S3 & $\begin{array}{c}30 \% \text { peat }+40 \% \text { coconut fibers }+20 \% \text { rice husk } \\
+10 \% \text { pumice }\end{array}$ & 7.7 & 186 & 79.4 & $0.30 \pm 0.01$ & $27.5 \pm 0.63$ & 252 & 4000 \\
\hline S4 & $\begin{array}{l}30 \% \text { peat }+40 \% \text { coconut fibers }+20 \% \text { wood fibers } \\
+10 \% \text { pumice }\end{array}$ & 7.2 & 119 & 81.2 & $0.33 \pm 0.00$ & $30.0 \pm 0.59$ & 361 & 5600 \\
\hline
\end{tabular}

${ }^{\text {*} W h e r e ~ s t a n d a r d ~ d e v i a t i o n ~ d o e s ~ n o t ~ a p p e a r ~ s t a n d a r d ~ e r r o r ~ i s ~ a l w a y s ~ l e s s ~ t h a n ~ 5 \% . ~}{ }^{\mathrm{I}} \mathrm{EN} 13652 .{ }^{2} \mathrm{ISO} 10694 .{ }^{5} \mathrm{Official}$ method $\mathrm{n}$ XV.2 -GU 248 
444

root hairs within the uppermost soil layer (Christanty et al., 1997; Kleinhenz and Midmore, 2001).

The photosynthetic capacity of the bamboo canopy is not only determined by the photosynthetic capacity of leaves, but also depends on the life span of leaves which influences the leafage structure of its canopy. It is generally recognized that photosynthetic activity of leaves steadily declines with age after full expansion. Photosynthesis rated up to three times higher in new $(<1$ year old $)$ leaves compared with those of older $(>1$ year old) leaves (Huang, 1986). This is attributed to greater metabolic activity of tissues (Huang, 1986) and higher nutrient concentrations (Kleinhenz and Midmore, 2001) in younger leaves.

Nutrient availability is the most important soil chemical property affecting significantly bamboo growth and yield but other factors such as soil $\mathrm{pH}$ and soil salinity are also important.

According to Shanmughavel and Francis (1997) who conducted research on other types of bamboo, nutrient application rates are suggested for seedlings and young plants of P.pubescens.

Considering this scientific contest, the present study was carried out using young seedlings and comparing different growing media and substrate regimes. Results are presented in Table 2. For all the parameters (number of culms, leaves and SPAD values) significant differences among treatments appeared from the second survey (after two months of cultivation). As it can be seen throughout the whole culture period, the best results were obtained by cultivating the bamboo in the substrate S1_A where the number of culms as well as the number of leaves and the SPAD values were promoted. It is also remarkable that this substrate yielded good results even with the $\mathrm{B}$ fertilization regime (half dose) demonstrating the fundamental role of the substrate composition in bamboo growing. In addition, the substrate containing the wood fibers (S4) was good both with both fertilization regimes, although the best values were obtained with the whole fertilizer quantity. Instead, the substrates containing rice husk did not present the expected results. In fact treatments $S 2$ and $S 3$ are statistically different from the others showing the worst performances.

The full fertilizer regime (A) had a positive effect by increasing the number of leaves, about $3 \%$ compared to the dose $\mathrm{B}$. The differences in the number of leaves concerning the two different fertilization regimes are summarized in Fig. 2 .

The good results obtained by using the substrates $S 1$ and $S 4$ and the differences related to the two fertilization regimes are also confirmed by the biomass evaluation. Table 3 shows the dry weight at the end of the observation period. Concerning the rooted part of the plants, it is interesting to notice the good performance obtained by the use of wood fibers in the growing medium S4_A. However, more research should be addressed to go deep in the use of this material in the substrate mixtures.

Similarly to several authors, we found that the use of organic matter in the medium can enhance the Phyllostachys plant growth and biomass. In fact it is a primary source of nutrients in the bamboo culture sites in Korea (Chung and Ramm, 1990; Kleinhenz and Midmore, 2001). Oshima (1931) stated that as with vegetable cultivation, bamboo requires abundant fertilizer and thus the reduction of fertilizers can be suggested more for the timber and ornamental productions, than for the shoots food production.

\section{Conclusions}

Nursers particularly appreciated the plant growth on a standard substrate and were very interested in how the plants responded to the thesis containing a higher percentage of wood fiber. After the end of this experiment, plants were transplanted into pots of a larger diameter and the results continue to confirm the goodness of the proposed solutions. Thus, bamboo should be managed with an ecosystem perspective that explicitly considers the ecological interactions within which they are embedded. The cultivation of the moso bamboo in Europe can be a good perspective as a future investment for nurseries.

\section{Acknowledgements}

The Authors thank Dr. Alberto Peyron (Vivai Purpurea s.r.l., Piobesi Torinese Italy) for the technical advise in plants growing. The authors thank also the Soil Chemical Laboratory of the Department of Agriculture, Forest and Food Science of the University of Turin for the substrates physical-chemical analysis.

Table 2. Comparison among the eight treatments of the average number of culms and leaves, and the SPAD values (mean value \pm standard deviation).

\begin{tabular}{|c|c|c|c|c|c|c|c|c|c|}
\hline \multirow{2}{*}{ Treatments } & \multicolumn{3}{|c|}{ Culms (n) } & \multicolumn{3}{|c|}{ Leaves (n) } & \multicolumn{3}{|c|}{ SPAD values } \\
\hline & 1st relief & 2nd relief & 3rd relief & 1st relief & 2nd relief & 3rd relief & 1st relief & 2nd relief & 3rd relief \\
\hline S1_A & $1.26 \pm 0.44^{\text {n.s. }}$ & $2.19 \pm 0.64^{\mathrm{a} *}$ & $2.72 \pm 0.81^{a}$ & $7.47 \pm 1.61^{a}$ & $13.44 \pm 3.21^{\mathrm{a}}$ & $19.16 \pm 5.13^{a}$ & $18.62 \pm 4.32^{\mathrm{a}}$ & $22.81 \pm 6.11^{\mathrm{a}}$ & $22.95 \pm 7.33^{\mathrm{a}}$ \\
\hline S2_A & $1.26 \pm 0.37$ & $2.22 \pm 0.62^{\mathrm{bc}}$ & $2.72 \pm 0.73^{\mathrm{bc}}$ & $7.44 \pm 1.74^{\mathrm{abc}}$ & $13.41 \pm 2.98^{\mathrm{bc}}$ & $19.06 \pm 4.72^{\mathrm{c}}$ & $18.98 \pm 4.27^{\mathrm{bc}}$ & $22.50 \pm 4.72^{c}$ & $22.77 \pm 6.35^{c}$ \\
\hline S3_A & $1.23 \pm 0.42$ & $2.25 \pm 0.59^{\mathrm{ab}}$ & $2.75 \pm 0.57^{\mathrm{cd}}$ & $7.25 \pm 1.35^{\mathrm{abc}}$ & $13.41 \pm 3.19^{\mathrm{b}}$ & $19.16 \pm 5.15^{\mathrm{c}}$ & $19.10 \pm 4.19^{\mathrm{bc}}$ & $22.99 \pm 3.99^{\mathrm{d}}$ & $22.93 \pm 3.20^{\circ}$ \\
\hline S4_A & $1.23 \pm 0.34$ & $2.22 \pm 0.55^{\mathrm{bcd}}$ & $2.69 \pm 0.76^{\mathrm{b}}$ & $7.22 \pm 1.59^{\mathrm{ab}}$ & $13.25 \pm 3.42^{\mathrm{b}}$ & $18.84 \pm 4.11^{\mathrm{b}}$ & $19.13 \pm 4.78^{b}$ & $22.68 \pm 5.20^{\mathrm{b}}$ & $22.56 \pm 7.58^{b}$ \\
\hline S1_B & $1.23 \pm 0.37$ & $2.19 \pm 0.63^{b}$ & $2.63 \pm 0.73^{b}$ & $7.22 \pm 1.57^{\mathrm{abc}}$ & $12.94 \pm 3.32^{\mathrm{b}}$ & $18.22 \pm 4.33^{\mathrm{b}}$ & $19.00 \pm 3.47^{\mathrm{bc}}$ & $22.34 \pm 5.88^{b}$ & $22.10 \pm 7.90^{b}$ \\
\hline S2_B & $1.26 \pm 0.34$ & $2.13 \pm 0.57^{\mathrm{cd}}$ & $2.53 \pm 0.59^{\mathrm{d}}$ & $7.13 \pm 1.01^{c}$ & $12.59 \pm 2.67^{\mathrm{c}}$ & $17.59 \pm 3.85^{\mathrm{cd}}$ & $19.18 \pm 4.65^{\mathrm{c}}$ & $22.15 \pm 4.16^{\mathrm{d}}$ & $21.62 \pm 3.00^{c}$ \\
\hline S3_B & $1.29 \pm 0.30$ & $2.09 \pm 0.50^{\mathrm{d}}$ & $2.47 \pm 0.61^{\mathrm{d}}$ & $7.09 \pm 1.33^{\mathrm{bc}}$ & $12.38 \pm 2.05^{c}$ & $17.19 \pm 3.79^{d}$ & $19.23 \pm 4.14^{\mathrm{bc}}$ & $21.74 \pm 4.74^{\mathrm{c}}$ & $21.46 \pm 4.11^{\mathrm{c}}$ \\
\hline S4_B & $1.29 \pm 0.40$ & $2.06 \pm 0.50^{\mathrm{d}}$ & $2.44 \pm 0.61^{\mathrm{d}}$ & $7.00 \pm 1.76^{\mathrm{ab}}$ & $12.22 \pm 3.97^{b c}$ & $16.88 \pm 4.36^{\mathrm{cd}}$ & $19.17 \pm 4.57^{\mathrm{bc}}$ & $21.73 \pm 3.97^{\mathrm{cd}}$ & $21.10 \pm 3.27^{\mathrm{c}}$ \\
\hline
\end{tabular}

n.s. No significance

${ }^{*}$ Different letters among treatments denote significant differences (Duncan test, $\mathrm{p}<0.05$ ) 
Table 3. Dry weights of the aerial and rooted parts of the bamboo seedlings after the production (mean value \pm standard deviation)

\begin{tabular}{ccc}
\hline & & \multicolumn{2}{c}{ Dry weights $(\mathrm{g})$} \\
\cline { 2 - 3 } Treatments & Aerial part & Rooted part \\
\hline S1_A & $2.68 \pm 0.50 \mathrm{a}^{*}$ & $1.05 \pm 0.10 \mathrm{a}$ \\
\hline S2_A & $2.01 \pm 0.17 \mathrm{~b}$ & $0.84 \pm 0.07 \mathrm{bc}$ \\
\hline S3_A & $1.94 \pm 0.18 \mathrm{~b}$ & $0.66 \pm 0.10 \mathrm{de}$ \\
\hline S4_A & $1.96 \pm 0.09 \mathrm{~b}$ & $0.97 \pm 0.09 \mathrm{ab}$ \\
S1_B & $2.05 \pm 0.09 \mathrm{~b}$ & $0.83 \pm 0.08 \mathrm{bc}$ \\
\hline S2_B & $1.77 \pm 0.15 \mathrm{~b}$ & $0.53 \pm 0.12 \mathrm{ef}$ \\
\hline S3_B & $1.65 \pm 0.21 \mathrm{~b}$ & $0.48 \pm 0.09 \mathrm{f}$ \\
\hline S4_B & $1.86 \pm 0.07 \mathrm{~b}$ & $0.80 \pm 0.06 \mathrm{~cd}$ \\
\hline
\end{tabular}

${ }^{*}$ Different letters among treatments denote significant differences (Duncan test, $\mathrm{p}<0.05)$

\section{References}

Chen JR, Shafi M, Li S, Wang Y, Wu J, YeZQ, Peng DL, Yan WB, Liu D (2015). Copper induced oxidative stresses, antioxidant responses and phytoremediation potential of moso bamboo (Phyllostachys pubescens). Scientific Reports 5:13554.

Chen JR, Shafi M, Wang Y, WuJ, YeZ, Liu C,ZhongB, GuoH, HeL, Liu D (2016). Organic acid compounds in root exudation of Moso Bamboo (Phyllostachys pubescens) and its bioactivity as affected by heavy metals. Environmentals Science and Pollution Research 23:2097720984.

Christanty L, Kimmins JP, Mailly D (1997). Without bamboo, the land dies: a conceptual model of the biogeochemical role of bamboo in an Indonesian agroforestry system. Forest Ecology and Management 91:83-91.

Chung YG, Ramm CW (1990). Relationships between soil-site properties and bamboo (Phyllostachys bambusoides) growth. Journal of Korean ForestrySociety 79(1):16-20.

Huang QM (1986). The research about biomass and photosynthesis of bamboo (Ph. pubescens). In: Higuchi T (Ed). Bamboo Production and Utilization. Proceedings of the Project Group P 5.04, Production and Utilization of Bamboo and related Species, XVIII IUFRO World Congress, Ljubljana, Yugoslavia, September 7-21, 1986. Kyoto: Wood Research Institute pp 77-81.

Kleinhenz V,MidmoreDJ (2001). Aspects of bamboo agronomy. Advances in Agronomy 74:99-145.

Komatsu H, Onozawa Y, Kume T, Shinohara Y, Otsuki K(2012). Canopy conductance for a moso bamboo (Phyllostachys pubescens) forest in western Japan. Agricultural and Forest Meteorology 156:111-120.

Lin Y, Lu JJ, Wu MD, Zhou MB, Fang W, Ide Y, Tang DQ (2014). Identification, cross-taxon transferability and application of full-length cDNASSR markers in Phyllostachyspubescens. SpringerPlus 3:486.

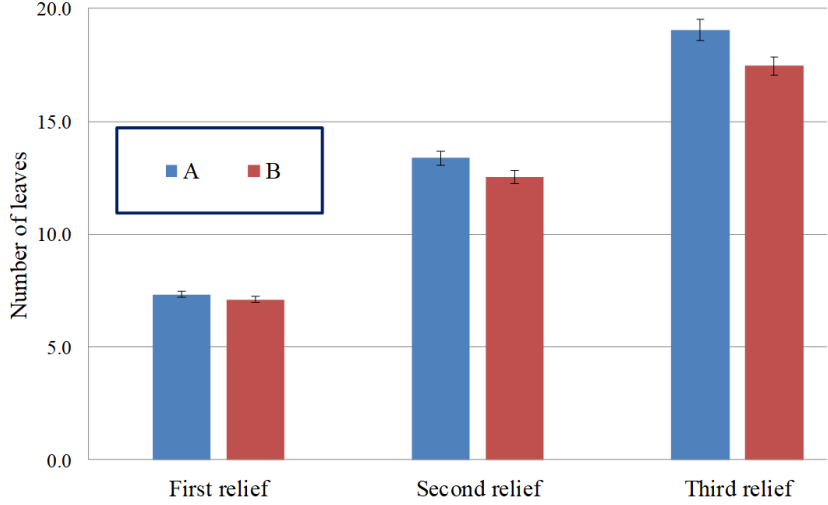

Fig. 2. Comparison of the average number of leaves depending on the different fertilization regime in the three reliefs (mean values with standard error bars). A: $1.6 \mathrm{~g} \mathrm{l-1} \mathrm{NPK} \mathrm{(16-11-10)}$ Osmocote Exact; ${ }^{\circ}$ B: 0.8 g 1-1 NPK (16-11-10) Osmocote Exact $^{\circ}$

Lobovikov M, Schoene D, Lou Y (2012). Bamboo in climate change and rural livelihoods. Mitigation and Adaptation Strategies for Global Change 17:261-276.

Oshima J (1931). The culture of moso bamboo in Japan. Part I: The plant, its uses, and how to start a moso plantation. Journal of the American BambooSociety 3:3-32.

Scurlock JMO, Dayton DC, Hames B (2000). Bamboo: an overlooked biomass resource?. Biomass Bioenergy 19:229-244.

Shanmughavel P, Francis K (1997). Balance and turnover of nutrients in a bamboo plantation (Bambusa bambos) of different ages. Biology and Fertility ofSoils Journal 25:69-74.

Wu J, Xu Q, Jiang P, Cao Z (2009). Dynamics and Distribution of Nutrition Elements in Bamboos. Journal of Plant Nutrition 32:489501.

Yang TH, Lee CH, Lee CJ, Cheng YW (2016). Effects of different thermal modification media on physical and mechanical properties of moso bamboo. Construction and Building Materials 119:251-259.

Yen TM (2015). Comparing aboveground structure and aboveground carbon storage of an age series of moso bamboo forests subjected to different management strategies. Journal of Forest Research 20:1-8.

Yen TM (2016). Culm height development, biomass accumulation and carbon storage in an initial growth stage for a fast-growing moso bamboo (Phyllostachyspubescens). Botanical Studies 57:10.

Yen TM, Ji YJ, Lee JS (2010). Estimating biomass production and carbon storage for a fast-growing makino bamboo (Phyllostachys makinoi) plant based on the diameter distribution model. Forest Ecology and Management 260:339-344.

Yen TM, Lee JS (2011). Comparing aboveground carbon sequestration between moso bamboo (Phyllostachys heterocycla) and China fir (Cunninghamia lanceolata) forests based on the allometric model. Forest Ecology and Management 261:995-1002. 